\title{
EU Enlargement and the EMU
}

\author{
Leo Michelis \\ Ryerson University \\ Minoas Koukouritakis \\ University of Crete
}

\begin{abstract}
This paper investigates empirically the extent to which the ten new EU countries are ready to join the European Monetary Union (EMU). Using France and Germany as a benchmark, we assess the prospects of successful EMU participation based on common trends analysis of the nominal convergence criteria as well as on real exchange rates and real per capita GDPs. The empirical results indicate that the new EU countries are partially ready to join the eurozone, and need further adjustments in their government policies to be fully prepared for joining the EMU.
\end{abstract}

- JEL Classification: F15, F33, F42

- Keywords: Economic Integration, EU Enlargement, Cointegration, Common Trends

\section{Introduction}

After growing in size from the original six members to twelve members and then to fifteen member states, the EU has recently experienced its biggest expansion ever in terms of scope and diversity. Of the thirteen countries that had applied to become members, ten countries joined the EU on May 1, 2004. These

\footnotetext{
*Corresponding address: Minoas Koukouritakis, Department of Economics, University of Crete, University Campus, 74100 Rethymno, Greece. Tel.: +302831077435, Fax: +302831077406, E-mail: minoas@econ.soc.uoc.gr

(c)2007-Center for International Economics, Sejong Institution, All Rights Reserved.
} 
countries are Cyprus, the Czech Republic, Estonia, Hungary, Latvia, Lithuania, Malta, Poland, the Slovak Republic and Slovenia ${ }^{1}$

Given their EU membership, another important question is the extent to which the 10 new countries can be ready to join the European Monetary Union (EMU), and thus increase the current size of the eurozone. The more ready they are the less the costs of adjusting their fiscal and monetary policies relative to the Eurozone's and the faster they will adopt the euro.

In the present paper we assess the prospects of the 10 new countries joining the EMU based on the nominal convergence criteria laid down by the Maastricht Treaty for a country's successful participation in the monetary union. Specifically, in order to qualify for joining the EMU a country:

(a) must have respected the normal fluctuation margins provided for by the exchange rate mechanism without severe tensions for at least the last 2 years before the examination. In particular, the member state must not have devalued its currency's central rate against the euro on its own initiative within this period;

(b) must have an inflation rate not higher than 1.5 per cent above the average of the three best-performing member states in terms of price stability;

(c) must have a long term interest rate not higher than 2 percentage points above the average of the three best-performing member states in terms of price stability;

(d) must have government deficit not exceeding 3 per cent of GDP at the end of the preceding financial year. If this is not the case, the ratio must have declined substantially and continuously and reached a level close to 3 per cent or, alternatively, must remain close to 3 percent while representing only an exceptional and temporary excess, and

(e) must have gross government debt not exceeding 60 per cent of GDP at the end of the preceding financial year. If this is not the case, the ratio must have sufficiently diminished and must be approaching the reference value at a satisfactory pace.

Clearly the conditions (a) to (e) impose constraints on the behavior of the exchange rates, interest rates, deficits and debts of the prospective member countries. For instance, even if individual interest rates may fluctuate and be nonstationary over time, the interest rates of all the countries should not deviate beyond two percentage points above the average of the three countries in the union with the lowest inflation rates. Similar arguments apply for the other variables in

'The other three countries are Bulgaria, Romania that hope to join by 2007, and Turkey that is currently negotiating to begin discussions for membership. 
the nominal convergence criteria.

The statistical notion of cointegration is well suited to study the co-movements of a set of variables in the long run. By definition, a set of nonstationary variables are cointegrated if there exist linear combinations (i.e. cointegrating relations) among them that are stationary. The cointegrating relations have the appealing economic interpretation of long run equilibrium relationships among the variables under study. In general if there exist $r$ cointegrating relations in a set of $p$ variables, there must also exist $p-r$ common stochastic trends that are nonstationary and move these variables around their equilibrium paths.

Even though most theoretical and empirical studies to date have been concerned with estimating and analyzing cointegrating relations ${ }^{2}$, common trends analysis can be equally useful and insightful. The identification and estimation of common trends in a set of economic variables can convey information that may be important and useful to applied economists and policy makers. Consider, for instance, the long term interest rates of France, Germany and the UK. If one finds two cointegrating relations among the three interest rates, then there must be a common stochastic trend shared among them. Identifying which country or combination of countries determines the common trend can be very useful information to policy makers for the design of their monetary policies.

In the present paper we use the Gonzalo and Granger (1995) methodology to identify, estimate and test for the number of common trends that lead to permanent

\footnotetext{
${ }^{2}$ The empirical literature relating to different aspects of the nominal convergence criteria in the EU has been extensive. Among others, Karfakis and Moschos (1990) used the bivariate framework of Engle and Granger (1987) to investigate interest rate linkages between Germany and each of the countries, Belgium, France, Ireland, Italy and the Netherlands. Using monthly data from 1979:4 to 1988:11, they found no evidence of cointegration in the pairs of interest rates. MacDonald and Taylor (1991) used monthly data from 1979:3 to 1988:12 to analyze bilateral US dollar nominal and real exchange rates for three EU countries (France, Germany and Italy) and three non-EU countries (Canada, Japan and Britain). Based on Johansen's multivariate cointegration method, these authors found some evidence of cointegration in the two types of exchange rates. Similarly, Hafer and Kutan (1994) adopted the multivariate cointegration framework to test for long run co-movements of short term interest rates and money supplies in a group of five EU countries. Using monthly data from 1979:3 to 1990:12, they reported evidence of partial policy convergence among these countries. Bayoumi and Taylor (1995) compared the behavior of real output growth and inflation of the countries participating in the Exchange Rate Mechanism (ERM) with a group of non-ERM countries. They concluded that the ERM had contributed to macro-policy coordination among the ERM members. Haug, MacKinnon and Michelis (2000) employed Johansen's cointegration approach to determine which EU countries would form a successful monetary union based on the Maastricht nominal convergence criteria. Using monthly and quarterly data of various time spans from 1979 to 1995 on 12 EU countries, these authors suggested that not all of the 12 countries would form a successful monetary union over time, unless several countries make significant adjustments in their fiscal and monetary policies.
} 
changes among the groups of nominal exchange rates, inflation rates, long term interest rates, deficits and debts of the 10 new EU members, in relation to 2 EMU countries, France and Germany. In addition to these sets of nominal variables, we also analyze the long run properties of real exchange rates and real per capita GDPs among these countries. Evidence of long run co-movements in the common trends in these real variables would strengthen the case for successful EMU enlargement by some or all the new countries.

It is useful to keep in mind that the notion of convergence used in this paper is different from the notions of absolute and conditional convergence used in the context of the empirical growth literature (e.g., see Barro and Sala-i-Martin (1995)). In the latter literature, convergence means that the real per capita gross domestic products of a group of countries attain the same value in the long run either unconditionally or after controlling for country characteristics due to differences of tastes and technologies across the countries. In the cointegration and common trends context of the present paper, convergence means that there exist long run relationships among a set of variables that tie them together in the long run without necessarily attaining the same value. Further such long run relationships can shift around over time if the underlying exogenous economic conditions (or common trends) change.

The rest of the paper is as follows. In Section 2 we outline the common trends models that we use in the paper. In Section 3 we describe the data and analyze the empirical results on cointegration and common trends. Briefly, the evidence suggests that there is weak partial co-movement of the nominal and real variables among the 10 new EU countries and the 2 EMU countries, suggesting that adjustment of policies of the new countries would be desirable if they wish to join the EMU successfully. In Section 4 we make some concluding remarks.

\section{The Cointegration and Common Trends Models}

In this section we outline the models that we employ in the subsequent empirical analysis. For this, we assume that the stochastic variables under consideration are integrated of order one, or $I(1)$, and that the data generating process is a Gaussian ${ }^{3}$ vector autoregressive model of finite order $k$, or $\operatorname{VAR}(k)$ which may possibly include some deterministic components. Let $Y_{t}$ be a $p$-dimensional column vector of $I(1)$ variables. Then the $\operatorname{VAR}(k)$ can be written in a vector error-correction model (VECM) form as 


$$
\Delta Y_{t}=\Pi Y_{t-1}+\sum_{i=1}^{k-1} \Gamma_{i} \Delta Y_{t-i}+\mu_{0}+\mu_{1} t+\varepsilon_{t}, \quad t=1 \ldots T
$$

where $\Pi$ and $\Gamma_{i}$ are $p \times p$ matrices of coefficients, $\mu_{0}$ and $\mu_{1}$ are $p \times 1$ vectors of constant and trend coefficients, respectively and $\varepsilon_{t}$ is a $p \times 1$ multivariate normal random error vector with mean vector zero and variance matrix $\Omega$ that is independent across time periods.

Under the hypothesis of cointegration $\Pi=\alpha \beta$, where $\alpha$ and $\beta$ are $p \times r$ matrices of full rank, the relation between $\alpha$ and the deterministic term $\mu_{t} \equiv \mu_{0}+\mu_{1} t$ is crucial for the properties of the process $Y_{t}$. To see this, first decompose $\mu_{0}$ and $\mu_{1}$ in the directions of $\alpha$ and $\alpha_{\perp}$, where $\alpha_{\perp}$ is a $p \times(p-r)$ matrix that is the orthogonal complement to $\alpha$ :

$$
\mu_{t}=\alpha \beta_{i}+\alpha_{\perp} \gamma_{i}, i=0,1
$$

where $\beta_{i}=\left(\alpha^{\prime} \alpha\right)^{-1} \alpha^{\prime} \mu_{i}$ and $\gamma_{i}=\left(\alpha_{\perp}^{\prime} \alpha_{\perp}\right)^{-1} \alpha_{\perp}^{\prime} \mu_{i}$. Next, following Johansen (1994), consider the following five submodels, which are ordered from the most to the least restrictive:

Model 0: $\mu_{t}=0$.

Model 1*: $\mu_{t}=\alpha \beta_{0}$.

Model 1: $\mu_{t}=\alpha \beta_{0}+\alpha_{\perp} \gamma_{0}$.

Model 2*: $\mu_{t}=\alpha \beta_{0}+\alpha_{\perp} \gamma_{0}+\alpha \beta_{1}$ t.

Model 2: $\mu_{t}=\alpha \beta_{0}+\alpha_{\perp} \gamma_{0}+\left(\alpha \beta_{1}+\alpha_{\perp} \gamma_{1}\right) t$.

The interpretation of these models becomes clear in the context of the solution of $Y_{t}$ in equation (1). The solution is given by

$$
Y_{t}=C \sum_{i=1}^{t} \varepsilon_{t}+\frac{1}{2} \tau_{2} t^{2}+\tau_{1} t+\tau_{0}+W_{t}+A
$$

where ${ }_{k} \underline{W}_{\mathrm{Y}}$ is a stationary process, $A$ is a vector such that $\beta^{\prime} A=0, C=\beta_{\perp}\left(\alpha_{\perp}{ }^{\top} \Gamma \beta_{\perp}\right)^{-1} \alpha_{\perp}{ }^{\prime}$, $\Gamma=I_{p}-\sum \Gamma_{i}, \beta_{\perp}$ is a $p \times(p-r)$ matrix of full rank that is orthogonal to $\beta$ and $\tau_{2}=C \mu_{1}^{=}$

The five submodels imply different behavior for the process $Y_{t}$ and the cointegrating relations $\beta^{\prime} Y_{t}$. Briefly, in Model $0, Y_{t}$ has no deterministic trend and all the stationary components have zero mean. In Model $1^{*}, Y_{t}$ has neither

${ }^{3}$ The Gaussian assumption is not necessary, but it is convenient for the derivation of asymptotic results. 
quadratic nor linear trend. However, both $Y_{t}$ and the cointegrating relations $\beta^{\prime} Y_{t}$ are allowed a constant term. In Model $1, Y_{t}$ has a linear trend, but the cointegrating relations $\beta^{\prime} Y_{t}$ have no linear trend. In Model $2^{*}, Y_{t}$ has no quadratic trend but $Y_{t}$ has a linear trend that is present even in the cointegrating relations. In Model 2, $Y_{t}$ has a quadratic trend but the cointegrating relations $\beta^{\prime} Y_{t}$ have only a linear trend.

It is clear from equation (3) that the common trends in $Y_{t}$ are contained in the first term of that expression. Given the definition of $C$, Johansen (1995, p. 41) defines the common trends by the cumulated disturbances $\alpha_{\perp}^{\prime} \sum \varepsilon_{t}$. Assuming that the common trends are a linear combination of $Y_{t}$, in the form $f_{t}=\alpha_{\perp}{ }^{\prime} Y_{t}$, Gonzalo and Granger proposed the following decomposition of any cointegrating system into its permanent and transitory (P-T) components:

$$
Y_{t}=A_{1} f_{t}+A_{2} z_{t}
$$

where, in addition to $f_{t}, z_{t}=\beta^{\prime} Y_{t}, A_{1}=\beta_{\perp}\left(\alpha_{\perp}^{\prime} \Gamma \beta_{\perp}\right)^{-1}$ and $A_{2}=a\left(\beta^{\prime} a\right)^{-1}$. Assuming that $\mu_{t}=0$, they also derive the MLE of $\alpha_{\perp}$ as the eigenvectors corresponding to the ( $p$ $r$ ) smallest eigenvalues of the problem

$$
\left|\lambda S_{00}-S_{01} S_{11}^{-1} S_{10}\right|=0 .
$$

where

$$
S_{i j}=T^{-1} \sum_{t=1}^{T} R_{i t} R_{j t}{ }^{\prime}, \quad i, j=0,1,
$$

in which $R_{0 t}$ and $R_{1 t}$ are residual matrices obtained from regressing $\Delta Y_{t}$ and $Y_{t-1}$ on $\Delta Y_{t-1} \cdots \Delta Y_{t-k}$ respectively.

Solving equation (5) for eigenvalues $1>\hat{\lambda}_{1}>\ldots>\hat{\lambda}_{p}>0$ and eigenvectors $\hat{M}=\left(\hat{m}_{1} \ldots \hat{m}_{p}\right)$, normalized such that $\hat{M}^{\prime} S_{00} \hat{M}=I$, we get the MLE of $\alpha_{\perp}$ as $\hat{\alpha}_{\perp}=\left(\hat{m}_{r+1} \ldots \hat{m}_{p}\right)$.

Given this framework, it is easy to test whether or not certain linear combinations of $Y_{t}$ can be common trends. Null hypotheses on $\alpha_{\perp}$ have the following form

$$
H_{0}: \alpha_{\perp}=G \theta
$$

where $G$ is a $p \times m$ known matrix of constants and $\theta$ is an $m \times(p-r)$ matrix of unknown coefficients such that $p-r \leq m \leq p$. To carry out the test, one solves the eigenvalue problem 


$$
\left|\lambda G^{\prime} S_{00} G-G^{\prime} S_{01} S_{11}^{-1} S_{10} G\right|=0
$$

for eigenvalues $1>\hat{\lambda}_{1}>\ldots>\hat{\lambda}_{m}^{*}>0$ and eigenvectors $\hat{M}^{*}=\left(\hat{m}_{1} \ldots \hat{m}_{m}^{*}\right)$, normalized such that $\hat{M}^{\prime}\left(G^{\prime} S_{00} G\right) \hat{M}^{*}=I$. We choose $\hat{\theta}_{m \times(p-r)}=\left(\hat{m}_{(m+1)-(p-r)} \ldots \hat{m}_{m}\right)$ and $\hat{\alpha}_{\perp}=G \hat{\theta}$. The likelihood ratio test statistic for testing $H_{0}$ is given by

$$
L=-T \sum_{i=r+1}^{p} \ln \left[\left(1-\hat{\lambda}_{i+(m-p)}\right) /\left(1-\hat{\lambda}_{i}\right)\right] .
$$

Under the null hypothesis $H_{0}: \alpha_{\perp}=G \theta$, the $L$-statistic in equation (9) is distributed as $\chi_{(p-r) \times(p-m)}^{2}$ asymptotically. In the next section, we make specific choices for the matrix $G$ and use the $L$-statistic in equation (9) to test various hypotheses of interest.

Gonzalo and Granger have derived their results assuming that $\mu_{t}=0$ in the VECM. In the present study, our model selection tests indicated that this is a restrictive assumption and Model $1 *$ describes best some variables in our data set. For this reason, we extent the VECM by the inclusion of a constant term. This extension does not invalidate the asymptotic distributions of $\hat{\alpha}_{\perp}$ and the $L$-statistic in (9). This follows from the fact that in computing these statistics, we obtain the residual matrices $R_{0 t}$ and $R_{1 t}$ by reduced rank regression of $\Delta Y_{t}$ and $\left(Y_{t-1}, 1\right)$ on the lagged differences $\Delta Y_{t-1} \cdots \Delta Y_{t-k}$. Then, the $\chi^{2}$-distribution of the $L$-statistic follows from the results in Johansen (1995); (see Corollary 11. 2, p. 161) and the duality of $\hat{\alpha}_{\perp}$ and $\hat{\beta}$, (p. 128).

\section{Data and Empirical Results}

\section{A. Data}

Most of the data for the present study were obtained from the CD-ROM of the International Financial Statistics (IFS) of the IMF, 2005. Other sources needed to complete the data set will be indicated below. We collected data for the 10 new EU and the 2 EMU countries, France and Germany. The sample is comprised of monthly or quarterly data of varying time spans determined by data availability. The starting date for the data was January 1993, when the Czech and the Slovak Republic became independent countries following the split of Czechoslovakia.

All exchange rates, interest rates and the real per capita GDPs (in euros) were expressed in natural logarithms. Monthly end-of period nominal exchange rates (units of domestic currency per euro) for all the countries were constructed for the 
period 1993:1 to 2003:12 using either line ae or ag of the $\operatorname{IFS}^{4}$. Monthly real exchange rates were calculated for the same period from monthly nominal exchange rates and monthly consumer price index (CPI) figures from line 64 of the IFS. In our analysis, Germany has been used as the benchmark country ${ }^{5}$. The CPI figures were also used to calculate monthly inflation rates.

The sample period for long term interest rates is 1997:1 to 2003:12. Monthly average long-term government bond yields for the Czech Republic were obtained from line 61 of the IFS. This IFS data series begins in January 2000. For the period 1997:1-1999:12 we used long-term government bond yields from the central bank of the Czech Republic. Line 61 of the IFS for the Slovak Republic begins in September 2000 and refers to 10 -year government bond yields. To complete the series, we collected data for the period 1997:1-2000:8 from the central bank of the Slovak Republic. For Poland, the long-term government bond yields were taken from the Polish Ministry of Finance, while for Hungary, Estonia, Lithuania, Slovenia, Malta and Cyprus the long term interest rates were taken from their respective central banks. For Latvia, the long-term interest rates were collected from the Central Statistical Bureau of the country. Finally, for the 2 EMU countries we used yields that refer to the 10-year government benchmark bond. These data series were collected from the central banks of France and Germany respectively.

Complete quarterly government deficit or surplus data are available only for Cyprus, the Czech Republic, Latvia, Poland, the Slovak Republic and the 2 EMU countries, and were obtained from line 80 of the IFS. The period covered for this variable is 1993:1 to 2003:4. For the Slovak Republic, the IFS data did not extend back to 1993:1 and we completed the series using data from the central bank of that country. Similarly for Cyprus, the data for the 2001:3-2003:4 were completed using data from the Cyprus Ministry of Finance. For Germany and France, the data for the 2002:2-2003:4 were completed using data from the central bank of the Germany and the French Ministry of Finance respectively. To construct the deficit/ GDP ratio, we used quarterly GDP from the line 99b of the IFS, except for Cyprus. Quarterly GDP data for Cyprus were obtained from the central bank of Cyprus.

\footnotetext{
${ }^{4}$ For the period through $31 / 12 / 1998$ we used the ECU instead of the euro in order to construct the exchange rates; thereafter the euro was used.

${ }^{5} \mathrm{~A}$ country's real exchange rate was calculated from the expression $\left(e^{*} P^{G E}\right) / P$, where $e$ is the nominal euro exchange rate of the country, $P^{G E}$ the German CPI and $P$ the domestic CPI. Since the introduction of euro in 1/1/1999, the real exchange rate of France relative to Germany was calculated from the expression $P^{G E} / P^{F R}$, which is the PPP exchange rate.
} 
For government debt, we used quarterly data for central government debt over the period 1996:1 to 2003:4. In the IFS CD-ROM, central government debt data are available only for Cyprus, the Czech Republic, Poland and the 2 EMU countries. For the 3 new EU countries government debt data were taken from line 88 of the IFS, while for the 2 EMU countries they were obtained from line $88 \mathrm{z}$ of the IFS. For the Czech Republic, Poland and France, the data for the 2003:12003:4 period were completed using data from their respective Ministries of Finance, while for Germany the data for the 2002:2-2003:4 period were completed using data from its central bank. For Cyprus, the data for the period 2001:3-2003:4 period were collected from the Cyprus Ministry of Finance. To construct the debt/ GDP ratios we followed the same procedure as we did for the deficit/GDP ratios.

Quarterly data for real per capita GDP in 1995 prices were calculated for 8 new EU countries $^{6}$ and the 2 EMU countries over the period 1993:1 to 2003:4. When available, real GDP data for these countries were obtained from line 99bp or 99br of the IFS (GDP volume in 1995 prices), except for Estonia and Cyprus. For Estonia, data in either line were not available and we deflated its nominal GDP (line 99b) with its 1995 base year deflator (line 99bip of the IFS). For Cyprus, real GDP was obtained by dividing nominal GDP with the CPI (line 64 of the IFS). The same procedure was followed to obtain Malta's real GDP. Real GDP for each country was converted to euros, using the 1995 quarterly nominal euro exchange rates. Finally, real GDP for each country was converted to real per capita GDP by dividing it with the population figure for each country (line $99 \mathrm{z}$ of the IFS) ${ }^{7}$.

\section{B. Cointegration Results}

In order to determine the number of common trends in each group of variables, it is necessary to determine, $r$, the number of cointegrating relations among them. To do this, we first tested each time series for unit roots using the Augmented Dickey-Fuller (ADF) test at the 5 percent level of significance. The lag length in the ADF test regression was chosen based on minimizing Akaike's information criterion.

\footnotetext{
${ }^{6}$ For Hungary and Poland data on real per capita GDP were available only for the 1995:1-2003:4 period, and for this reason we dropped these two countries from this specific sample.

${ }^{7}$ Population figures are available only in annual frequency in the IFS CD-ROM and refer to mid-year estimates. For this reason, we made the plausible assumption that there is no significant change in the population of a country among quarters of the same year, and we obtained estimates of quarterly real per capita GDP by dividing real GDP with the population figure for each country.
} 
Table 1. Augmented Dickey-Fuller test for a unit root ${ }^{\mathrm{a}}$

\begin{tabular}{llcccccc}
\hline Country & $\begin{array}{c}\text { Nominal } \\
\text { exchange } \\
\text { rates }\end{array}$ & $\begin{array}{c}\text { Inflation } \\
\text { rates }\end{array}$ & $\begin{array}{c}\text { Long term } \\
\text { interest } \\
\text { rates }\end{array}$ & $\begin{array}{c}\text { Deficit/ } \\
\text { GDP } \\
\text { ratios }\end{array}$ & $\begin{array}{c}\text { Debt/ } \\
\text { GDP } \\
\text { ratios }\end{array}$ & $\begin{array}{c}\text { Real } \\
\text { exchange } \\
\text { rates }\end{array}$ & $\begin{array}{c}\text { Real capita } \\
\text { GDPs }\end{array}$ \\
\hline Cyprus & -1.87 & $-3.62^{*}$ & -1.68 & -1.08 & -2.02 & -2.15 & -2.80 \\
Czech Rep. & -1.68 & -3.05 & -2.82 & -1.03 & -1.22 & -2.78 & -2.70 \\
Estonia & -1.70 & -2.74 & -1.12 & & & $-6.19^{*}$ & $-3.87^{*}$ \\
Hungary & $-3.45^{*}$ & -2.69 & -1.39 & & & -2.45 & \\
Latvia & $-3.49^{*}$ & $-4.18^{*}$ & $-3.99 *$ & & & $-5.13^{*}$ & -2.57 \\
Lithuania & -2.19 & $-3.86^{*}$ & -1.13 & & & $-4.88^{*}$ & -2.86 \\
Malta & -1.24 & $-9.49^{*}$ & 0.01 & & & -1.40 & -2.34 \\
Poland & $-2.91^{*}$ & $-6.13^{*}$ & -1.76 & & 0.30 & -1.60 & \\
Slovak Rep. & -2.32 & $-9.13^{*}$ & -0.17 & $-5.15^{*}$ & & $-3.55^{*}$ & -2.21 \\
Slovenia & $-4.50^{*}$ & $-5.65^{*}$ & -1.52 & & & -2.56 & -1.79 \\
France & $-1.55^{\mathrm{b}}$ & $-2.22^{*}$ & -2.54 & -1.36 & 0.61 & -2.10 & -1.32 \\
Germany & $-1.27^{\mathrm{b}}$ & $-2.48^{*}$ & -2.71 & -2.42 & -1.34 & & -1.94 \\
\hline
\end{tabular}

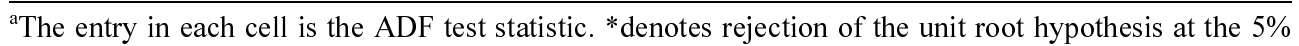
significance level. For the variables of the table, the sample sizes are 132, 131, 84, 44, 32, 132 and 44 respectively. We also tested the null hypothesis of a second unit root. This hypothesis was rejected in all cases. ${ }^{\mathrm{b}}$ Sample size is 72 .

The unit root results are presented in Table 1. As shown in Table 1, we fail to reject the unit root hypothesis for most of the series but not for all the countries in the sample. In the case of nominal exchange rates, the unit root hypothesis is rejected for Hungary, Latvia, Poland and Slovenia ${ }^{8}$. Inflation does not have a unit root for Cyprus, Latvia, Lithuania, Malta, Poland, the Slovak Republic, Slovenia, France and Germany. Similarly, real exchange rates are found to be stationary for the three Baltic countries and the Slovak Republic, while interest rates are stationary only for Latvia. In the case of the deficit/GDP ratio, the unit root hypothesis is rejected for Latvia, Poland and the Slovak Republic. On the other hand, the debt/GDP ratio has a unit root for all the 5 countries in the sample. Finally, real per capita GDP is stationary only for Estonia. In all the cases where the unit root hypothesis was not rejected, we tested the null hypothesis of a second unit root. This hypothesis was rejected in all cases.

Based on these results we proceeded with cointegration and common trends analysis of the relevant sets of variables. For this part, we dropped all the variables from the sample that were stationary based on the ADF test results. Thus, the

\footnotetext{
${ }^{8}$ The sample period for the unit root tests in the nominal exchanges rates of France and Germany was 1993:1 to $1998: 12$, as these countries adopted the euro in 1/1/1999.
} 
dimension of each VECM was determined both by the number of non-stationary components for each set of variables and by the number of countries in each subgroup of counties we analyzed.

For the cointegration analysis, we first selected the lag length, $k$, in equation (1), by setting up a separate VECM for each set of variables and using the likelihood ratio test. We started from a maximum length of lag $k=12$ for the variables with monthly data and $k=4$ for the variables with quarterly data. Under the hypothesis $\Gamma_{k}=0$, the likelihood ratio test is asymptotically distributed as $\chi^{2}$ with $p^{2}$ degrees of freedom; see Johansen (1995, p. 21). Further, to determine which submodel describes best each set of variables, we tested the submodels against each other using the likelihood ratio tests in Johansen (1995, Chapter 11, Corollary 11.2 and Theorem 11.3, pp. 161-162).

Table 2 reports the Trace statistics of Johansen and Juselius (1990) for nominal exchange rates, inflation, long term interest rates, deficit/GDP ratios, debt/GDP

Table 2. Trace statistics

\begin{tabular}{|c|c|c|c|c|c|c|c|c|c|}
\hline$(p-r)$ & $\begin{array}{c}\text { Nominal } \\
\text { exchange } \\
\text { rates }\end{array}$ & $\begin{array}{c}\text { Inflation } \\
\text { differe- } \\
\text { ntials }\end{array}$ & $\begin{array}{c}\text { Long term } \\
\text { interest } \\
\text { rates }\end{array}$ & $\begin{array}{l}\text { Deficit/ } \\
\text { GDP } \\
\text { ratios }\end{array}$ & $\begin{array}{l}\text { Debt/ } \\
\text { GDP } \\
\text { ratios }\end{array}$ & $\begin{array}{c}\text { Real } \\
\text { exchange } \\
\text { rates }\end{array}$ & $\begin{array}{c}\text { Real per } \\
\text { capita } \\
\text { GDPs }\end{array}$ & $\begin{array}{c}5 \% \text { critical } \\
\text { values for } \\
\text { Model } 0\end{array}$ & $\begin{array}{l}5 \% \text { critical } \\
\text { values for } \\
\text { Model } 1 *\end{array}$ \\
\hline 11 & & & $341.15^{*}$ & & & & & 263.25 & 298.16 \\
\hline 10 & & & $255.45^{*}$ & & & & & 219.38 & 251.31 \\
\hline 9 & & & $197.05^{*}$ & & & & $383.16^{*}$ & 179.48 & 208.41 \\
\hline 8 & & & $149.67 *$ & & & & $255.34 *$ & 143.64 & 169.54 \\
\hline 7 & & & 107.47 & & & $148.20^{*}$ & $163.82 *$ & 111.79 & 134.70 \\
\hline 6 & $110.84 *$ & & 73.70 & & & 99.14 & $102.85^{*}$ & 83.94 & 103.84 \\
\hline 5 & 55.68 & & 47.13 & & 54.61 & 62.79 & 58.39 & 60.06 & 76.96 \\
\hline 4 & 31.81 & & 28.91 & 22.88 & 29.53 & 36.11 & 30.15 & 40.17 & 54.09 \\
\hline 3 & 17.88 & $59.75^{*}$ & 14.54 & 9.88 & 15.23 & 20.31 & 18.26 & 24.28 & 35.19 \\
\hline 2 & 8.46 & $20.23 *$ & 7.94 & 2.25 & 5.74 & 9.77 & 8.50 & 12.32 & 20.25 \\
\hline 1 & 2.34 & 3.65 & 2.26 & 0.09 & 1.32 & 3.50 & 3.47 & 4.13 & 9.17 \\
\hline$k^{\mathrm{a}}$ & 2 & 2 & 1 & 3 & 1 & 2 & 1 & & \\
\hline Model & $1 *$ & 0 & 0 & 0 & 0 & $1 *$ & 0 & & \\
\hline
\end{tabular}

The value reported at the top of each column is for $r=0$, so that $p-r=p$, where $p$ is the number of countries included. *denotes rejection of the null hypothesis of at most $r$ cointegrating relations at the $5 \%$ significance level. ${ }^{\mathrm{a}} \mathrm{k}$ indicates the lag intervals.

\footnotetext{
${ }^{9}$ These tests are also distributed as $\chi^{2}$ with degrees of freedom determined by the pairs of models being tested as follows: $0 \underset{r}{\subset} 1 \underset{p-r}{*} 1 \underset{r}{\subset} 2 * \underset{p-r}{\subset}$.
} 
ratios, real exchange rates and real per capita GDPs, along with the 5 percent critical values for the appropriate submodels that were estimated ${ }^{10}$.

As shown in Table 2, the 6-dimensional system of nominal exchange rates for the six new EU countries ${ }^{11}$ (excluding Hungary, Latvia, Poland and Slovenia with $I(0)$ nominal exchange rates), has one cointegrating vector and five common trends. The 11-dimensional system of long term interest rates (excluding Latvia) has four cointegrating vectors and seven common trends. No evidence of cointegration exists in the 4-dimensional system of the deficit/GDP ratios (including Cyprus, the Czech Republic, France and Germany) and in the 5dimensional system of the debt/GDP ratios (including Cyprus, the Czech Republic, Poland, France and Germany). In the case of the inflation rates, since the French and German inflation rates are stationary, we estimated a 3-dimensional system of inflation differentials relative to Germany, for the Czech Republic, Estonia and Hungary, and found two cointegrating vectors and a single common trend ${ }^{12}$.

On the real side, the 7-dimensional system of real exchange rates (excluding the three Baltic countries and the Slovak Republic with $\mathrm{I}(0)$ real exchange rates) has one cointegrating vector and six common trends. For real per capita GDPs, we set up a 9-dimensional system for Cyprus, the Czech Republic, Latvia, Lithuania, Malta, the Slovak Republic, Slovenia, France and Germany. The results indicate four cointegrating vectors and five common trends. Clearly, the real exchange rates and the real per capita GDPs of the new EU countries and the 2 EMU countries have more common trends than cointegrating relations in their respective VECMs. This points to the real differences that exist in the structures of these economies that may relate to differences in productivity potentials and in the expectations of the future course of their fiscal and monetary policies. Much work may be required in terms of adjustments of their monetary and especially fiscal policies so that they can converge to a single common trend over time. For example, tax and

\footnotetext{
${ }^{10}$ MacKinnon, Haug and Michelis (1999) have computed highly accurate critical values for the Trace statistic using the response surface methodology. These critical values differ substantially from those existing in the literature, especially when the dimension of the VECM is large; e.g., compare to Osterwald-Lenum (1992). Since we deal with large dimensional systems in this study, we use these new critical values for testing hypotheses.
${ }^{11}$ France and Germany were not included in the system of nominal exchange rates since they adopted the euro in $1 / 1 / 1999$.
${ }^{12}$ For the inflation differentials, the ADF test statistics were -1.59 for the Czech Republic, -1.99 for Estonia and -0.89 for Hungary. In all cases the null hypothesis of a unit root is not rejected at the 5 percent level of significance.


expenditure harmonization across the new countries, along with monetary adjustment, will increase the prospects for successful EMU accession, by increasing the number of cointegrating relations and thus, reducing the number of common trends.

These results show clearly that, except for the inflation rates ${ }^{13}$, the systems of all the other variables have more common trends than cointegrating relations that bind them together in the long run. The deficit/GDP and the debt/GDP ratios are not bound together even by a single cointegrating vector. This evidence, in turn, indicates partial convergence of policies among the new EU countries and the 2 largest EMU countries ${ }^{14}$.

\section{Common Trends Results}

In this section we decompose each system of variables into its permanent and transitory components and we analyze the common stochastic trends, in order to see which country or group of countries, if any, contribute significantly to them. This is potentially useful information for the design and adjustment of policies within each country and the EU.

Consider, for instance, the inflation rates of Germany, Poland, and Hungary, and suppose this 3-dimensional system has one cointegrating vector and two common trends, dominated by Germany alone. Then, in this hypothetical scenario, the German inflation rate is an exogenous variable, determined, possibly, by that country's current and expected future monetary and fiscal policies and by fundamental real factors such the future productivity prospects of the German economy. The other two inflation rates are endogenous and changes in the German inflation rate will affect both their transitory (stationary) and permanent components. Alternatively, changes in either the Polish or the Hungarian inflation rate or both will have only a temporary impact on the long run equilibrium relationship of the three inflation rates without being able to alter it in a permanent way. Consequently, the driving force in this system of inflation rates is the German

\footnotetext{
${ }^{13}$ The convergence of inflation rates to single trend is a positive finding, but this is, perhaps, due to the global fight to contain inflation in the last decade or so, than to coordinated monetary policies on the part of all the countries in our sample.

${ }^{14}$ For the interpretation of the empirical results, we will claim that there is "complete" convergence of government policies in a group of $\mathrm{p}$ countries, if we find that there exist $r=p-1$ cointegrating vectors and a single shared common stochastic trend in a set of policy variables such as inflation rates. On the other hand, if $0<r<p-1$, then there is only "partial" convergence among the policies of the countries concerned; see Hafer and Kutan (1994) and Haug et al. (2000).
} 
Table 3. The estimated $a_{\perp}{ }^{\prime} \mathrm{s}$

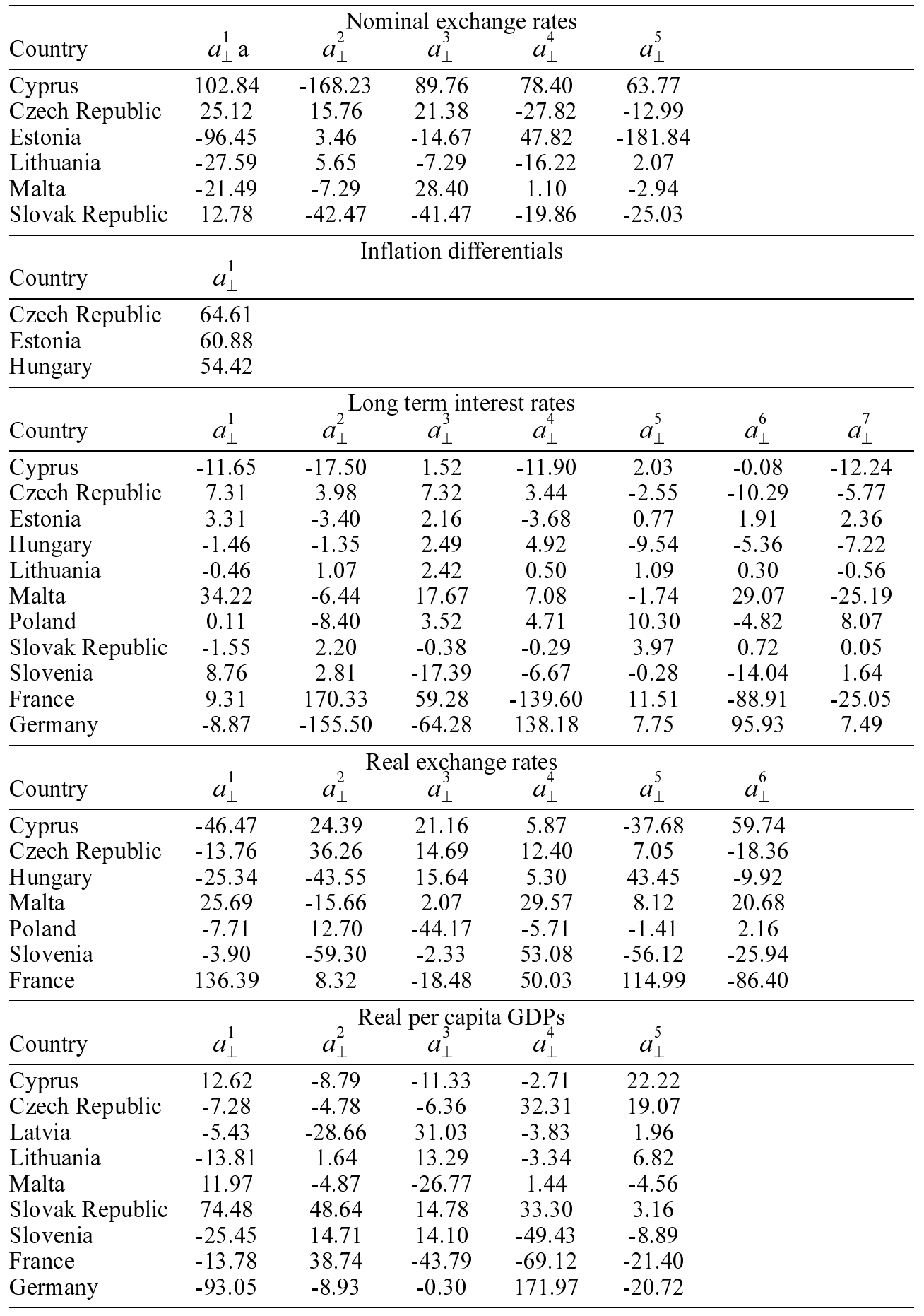

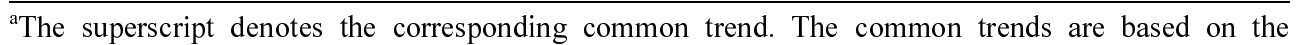
normalization $M S_{00} M=I$. 
monetary policy and if Poland and Hungary wish to achieve inflation rates similar to the German inflation rate, they must adjust their monetary policies in the direction of the German monetary policy.

The columns of Table 3 provide estimates of the linear combinations $\left(\hat{a}_{\perp}\right)$ that enter each of the common trends for the systems of nominal exchange rates, real exchange rates, inflation, long term interest rates and real per capita GDP for the new EU countries and the 2 EMU countries ${ }^{15}$. Figures 1 to 4 show examples of the P-T decomposition, based on equation (4), in each of the systems of nominal

Figure 1. P-T decomposition of the nominal exchange rates
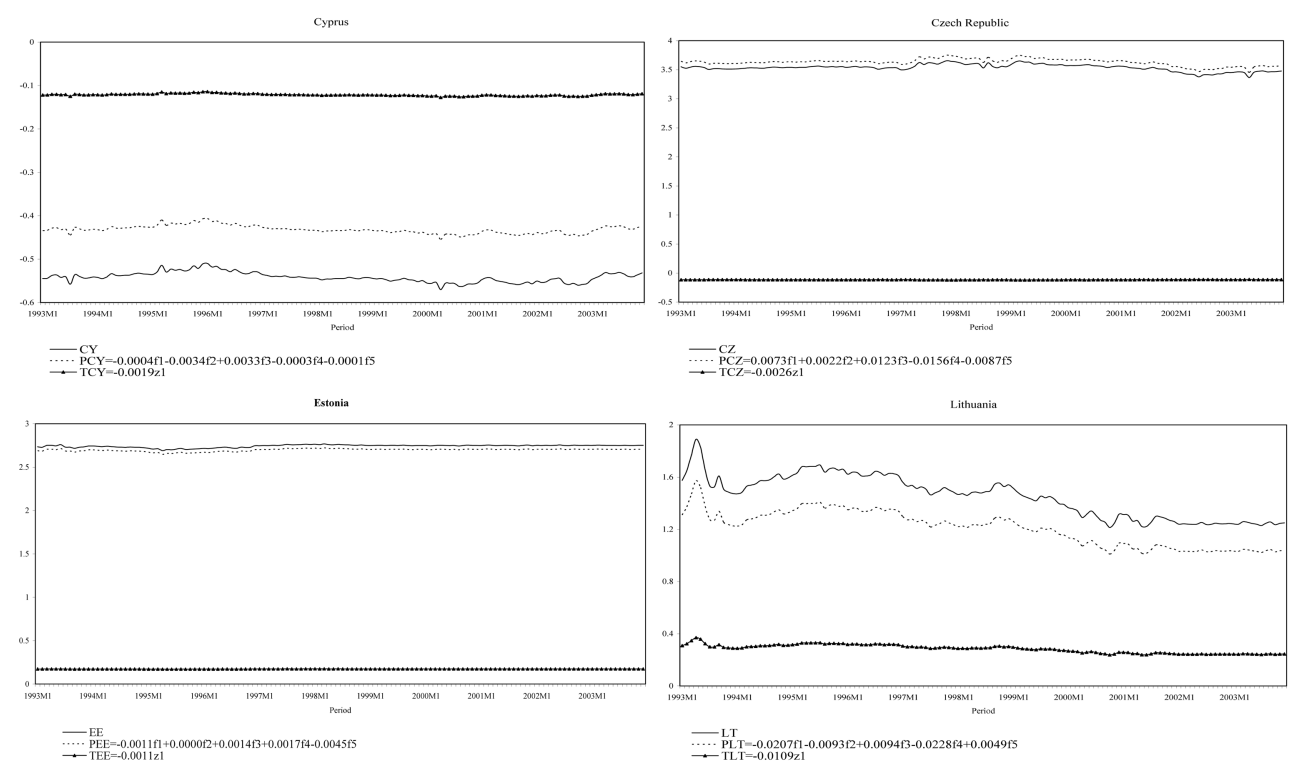

Malta
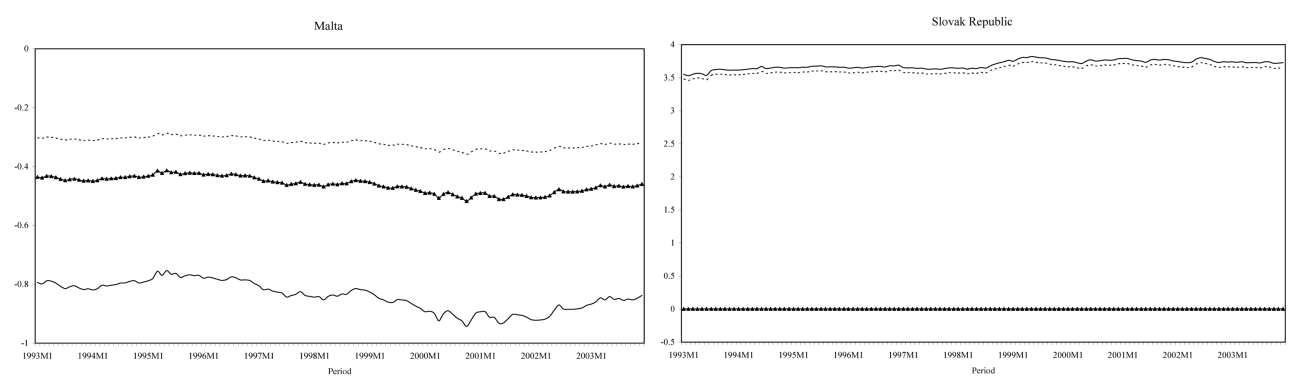

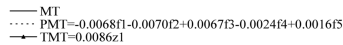

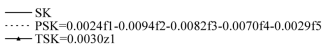

\footnotetext{
${ }^{15}$ The deficit/GDP and debt/GDP ratios have no cointegrating vectors and therefore cannot be decomposed into transitory and permanent components. Also, for the reason mentioned above, we do not consider the combined system of nominal exchange rates.
} 
exchange rates, long term interest rates, real exchange rates and real per capita GDPs. Notice that the plots in each figure are informative in two useful ways. First, they point to the same number of common trends as identified by the trace test. Second, they reveal information as to which countries' permanent components are important. For example, as seen from Figure 1, the five permanent components in the system of nominal exchange rates correspond to Cyprus, the Czech Republic, Estonia, Lithuania and the Slovak Republic.

Table 4 reports the $L$-statistics for the sets of variables in the combined system of the new EU countries and the 2 EMU countries. For the nominal exchange rates, we tested the null hypothesis that the five countries, pointed to by Figure 1, have a common permanent component among the five $I(1)$ country factors. In this case,

Table 4. Testing for linear combinations on the common trends

\begin{tabular}{|c|c|c|c|}
\hline \multicolumn{4}{|c|}{ Nominal exchange rates } \\
\hline$H_{0}{ }^{\mathrm{a}}$ & $L$-statistic & $\chi^{2}(p-r) \times(p-m)$ & $(p-r) \times(p-m)$ \\
\hline Countries to which the $\mathrm{P}$ components correspond & $19.88 *$ & 11.07 & 5 \\
\hline \multicolumn{4}{|c|}{ Inflation differentials } \\
\hline$H_{0}$ & $L$-statistic & $\chi^{2}(p-r) \times(p-m)$ & $(p-r) \times(p-m)$ \\
\hline Czech Republic & $19.45^{*}$ & 5.99 & 2 \\
\hline Estonia & $8.28 *$ & 5.99 & 2 \\
\hline Hungary & $7.81^{*}$ & 5.99 & 2 \\
\hline \multicolumn{4}{|c|}{ Long term interest rates } \\
\hline$H_{0}$ & $L$-statistic & $\chi_{(p-r) \times(p-m)}^{2}$ & $(p-r) \times(p-m)$ \\
\hline Countries to which the $\mathrm{P}$ components correspond & $84.42 *$ & 41.34 & 28 \\
\hline "Enlargement core" + 2 EMU countries & $77.94 *$ & 41.34 & 28 \\
\hline $\mathrm{CEE}$ countries $^{\mathrm{b}}+2$ EMU countries & $65.05^{*}$ & 23.68 & 14 \\
\hline \multicolumn{4}{|c|}{ Real exchange rates } \\
\hline$H_{0}$ & $L$-statistic & $\chi^{2}(p-r) \times(p-m)$ & $(p-r) \times(p-m)$ \\
\hline Countries to which the $\mathrm{P}$ components correspond & $26.33 *$ & 12.59 & 6 \\
\hline "Enlargement core" + France & $31.65^{*}$ & 12.59 & 6 \\
\hline \multicolumn{4}{|c|}{ Real per capita GDPs } \\
\hline$H_{0}$ & $L$-statistic & $\chi_{(p-r) \times(p-m)}^{2}$ & $(p-r) \times(p-m)$ \\
\hline Countries to which the $\mathrm{P}$ components correspond & $182.81^{*}$ & 31.41 & 20 \\
\hline "Enlargement core" +2 EMU countries & $174.81 *$ & 25.00 & 15 \\
\hline
\end{tabular}

${ }^{\mathrm{a}} H_{0}$ : The respective country or group of countries contributes significantly to the common trend(s). *denotes rejection of the null hypothesis at the $5 \%$ significance level. ${ }^{b}$ Excluding Latvia. ${ }^{\circ}$ Excluding Hungary. 
the $G$ matrix has the following form:

$$
G=\left[\begin{array}{lllll}
1 & 0 & 0 & 0 & 0 \\
0 & 1 & 0 & 0 & 0 \\
0 & 0 & 1 & 0 & 0 \\
0 & 0 & 0 & 1 & 0 \\
0 & 0 & 0 & 0 & 0 \\
0 & 0 & 0 & 0 & 1
\end{array}\right]
$$

where the number of rows is determined by the dimension of the system ( 6 nominal exchange rates) and the number of columns is determined by the number of common trends ( 5 in this case). As Table 4 indicates, this null hypothesis is rejected at the 5 percent level of significance.

For the inflation differentials of the Czech Republic, Estonia and Hungary relative to Germany we tested the hypothesis that each of the three countries respectively dominates the single common trend. As shown in Table 4 this hypothesis is also rejected at the 5 percent level of significance ${ }^{16}$. Hence, the inflation differentials are endogenous and can be affected by the policy actions within each country. Evidently in this case, the adjustment has taken place in the direction of low inflation policies that has been traditionally the cornerstone of the German monetary policy. In this sense, the German monetary policy has been the anchor of the monetary policies of these three new EU countries. This is shown clearly in Figure 5 which shows that the inflation rates of the three countries have converged over time to the German inflation rate.

For the long term interest rates, we tested the null hypothesis of a common permanent component among the seven common trends of (a) the seven countries identified in Figure 2 (i.e. Cyprus, the Czech Republic, Hungary, Malta, Poland, Slovenia and Germany), (b) an "enlargement core" of five new EU countries together with the 2 EMU countries, where the "enlargement core" consists of the 5 new EU countries with the highest real per capita GDP, namely Cyprus, Slovenia, Malta, the Czech Republic and Hungary, and (c) the Central and Eastern European

\footnotetext{
${ }^{16} \mathrm{We}$ also carried out the same test for each of the three possible pairs of countries. In every instance the null hypothesis was rejected. These results are available from the authors upon request.

${ }^{17}$ The group of the Central and Eastern European countries consists of the 8 former centrally planned economies, namely the Czech Republic, the three Baltic countries, Hungary, Poland, the Slovak Republic and Slovenia. In the case of interest rates Latvia is excluded, because the results indicated that the country's long term interest rate is $I(0)$.
} 
Figure 2. P-T decomposition of the interest rates
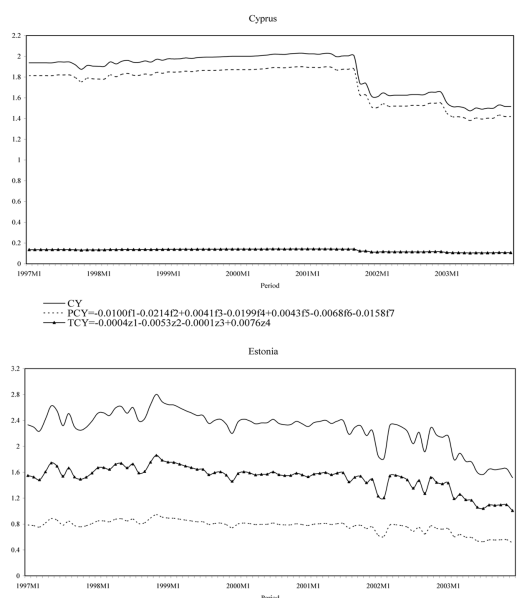

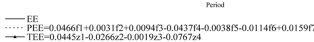

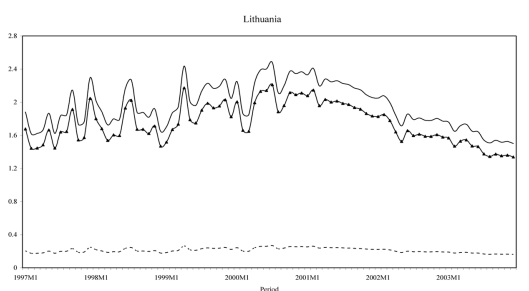

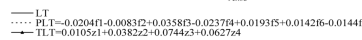

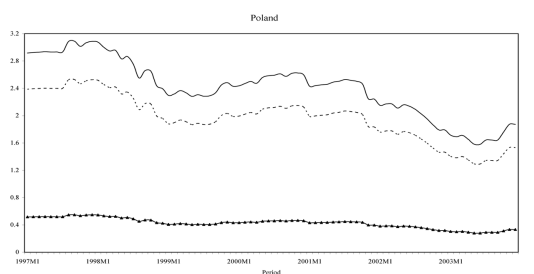

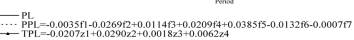

Sloveni

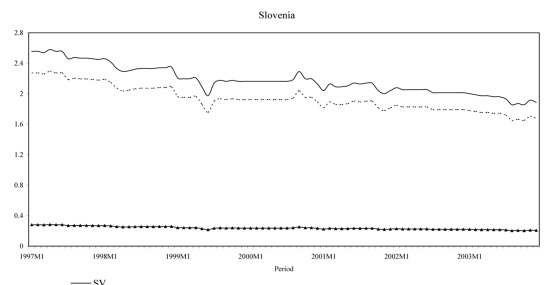

- MV

Germant
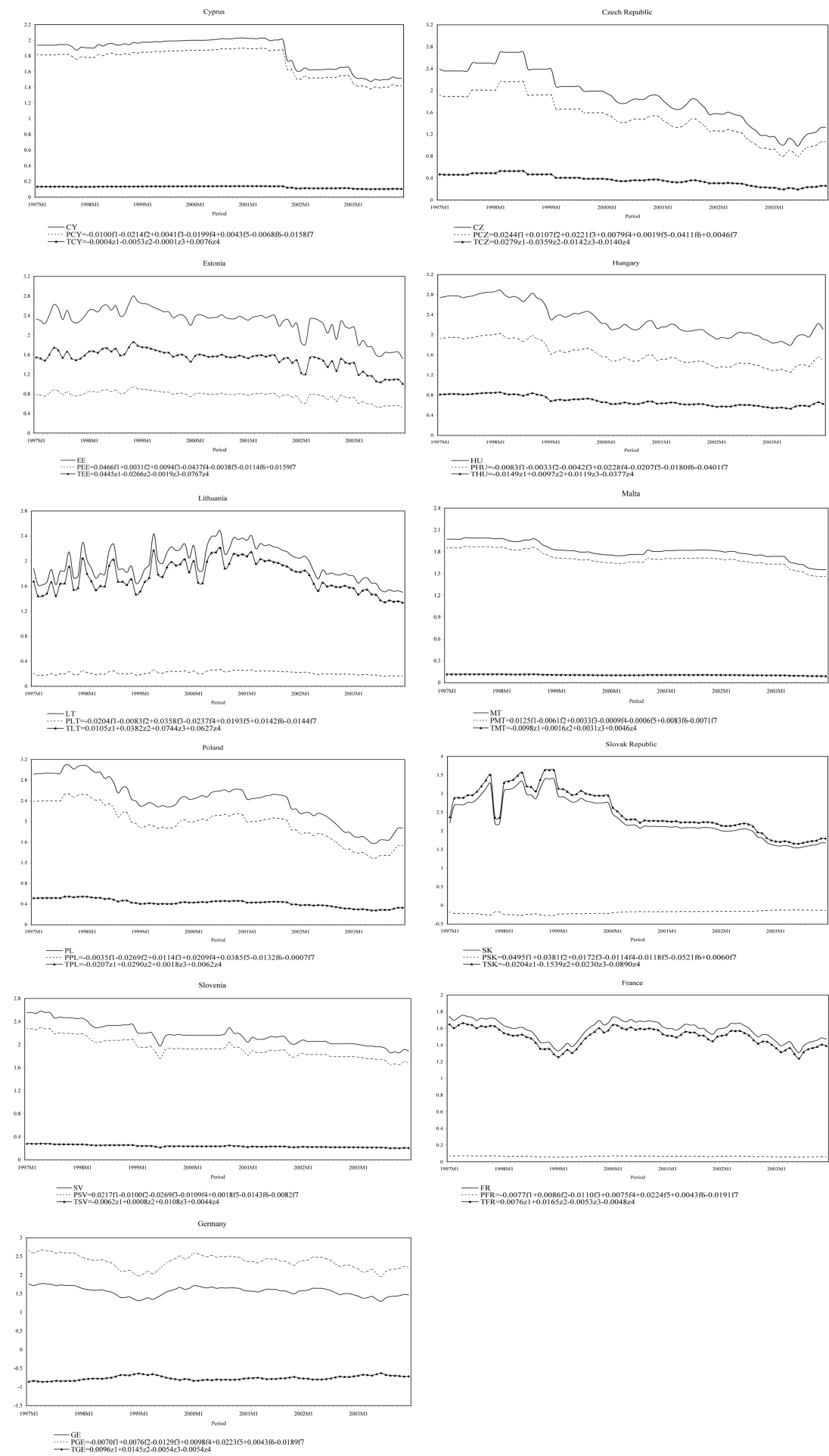

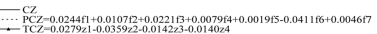
Hungans

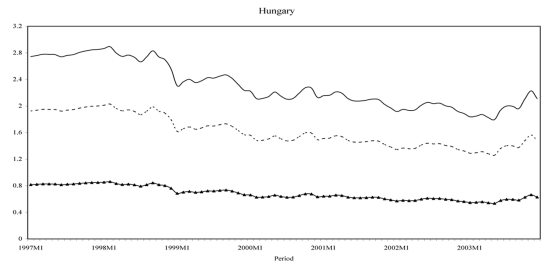

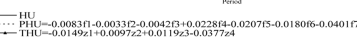

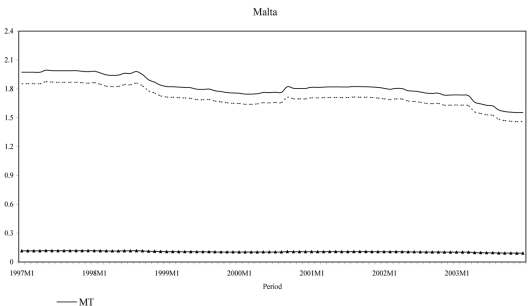

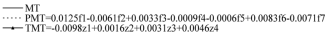

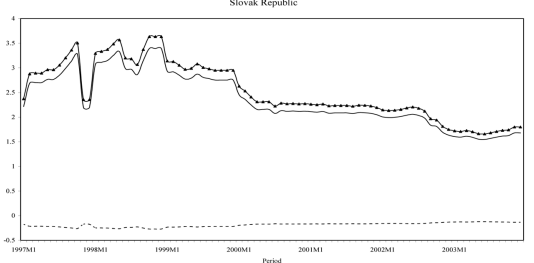

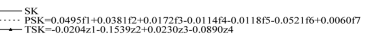

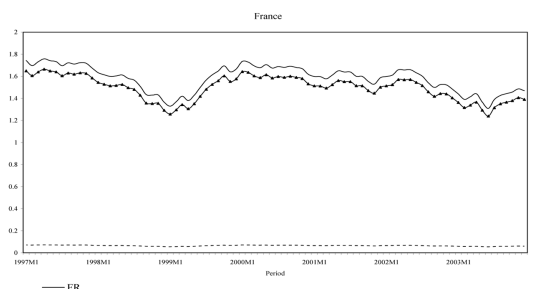

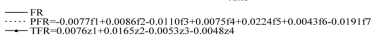

-...FE 
Figure 3. P-T decomposition of the real exchange rates
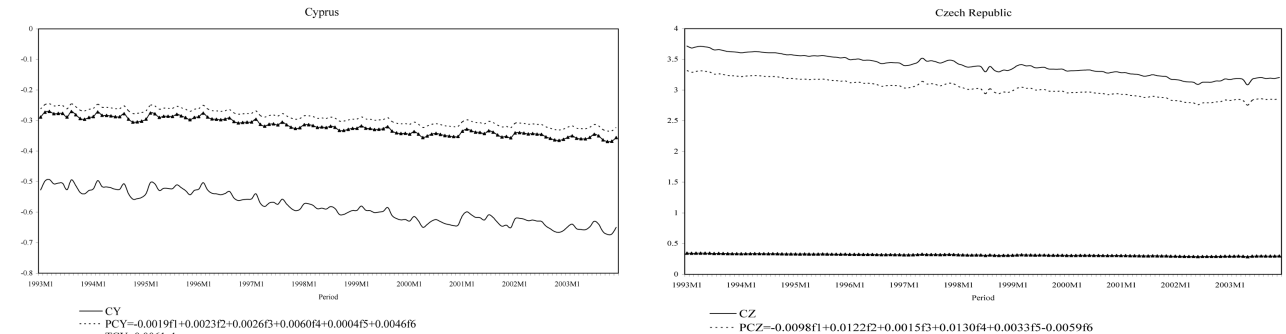

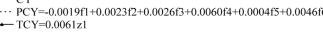

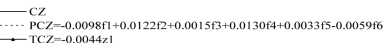

Hungary
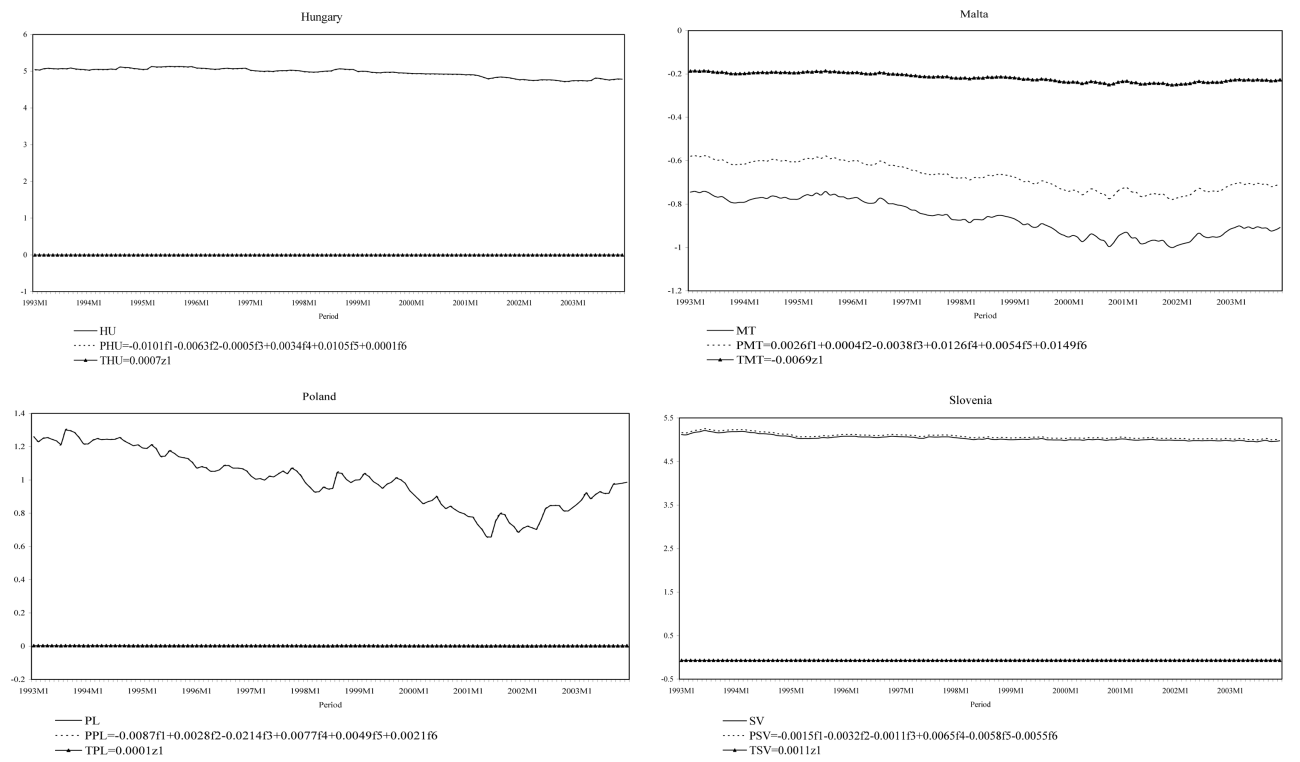

Slovenia
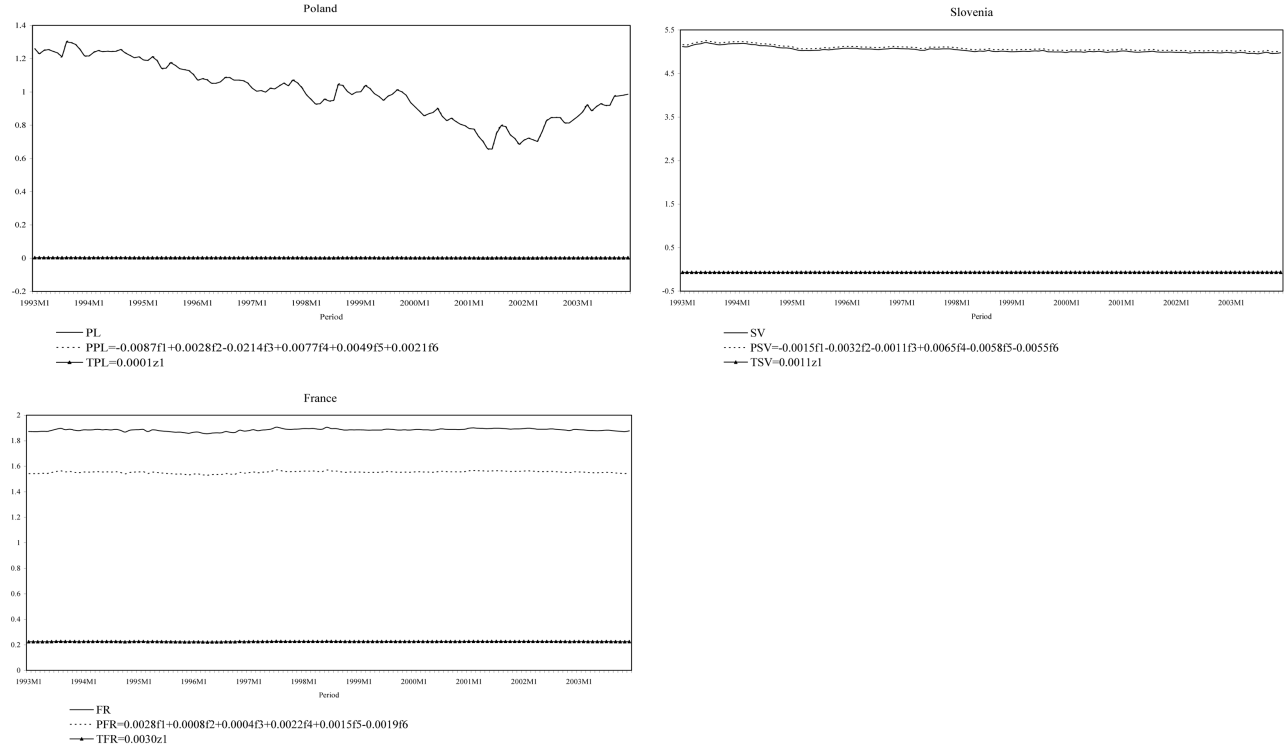

countries $(\mathrm{CEE})^{17}$ together with the 2 EMU countries. The reason for hypothesis (c) is that, since the early 1990 s, the CEE countries have adopted market oriented policies and have attempted to develop and liberalize their financial markets. All three hypotheses are rejected at the 5 percent level of significance. Thus, there is no evidence that the long term interest rates have a significant common permanent component in every instance, which drives the system of long term interest rates in 
Figure 4. P-T decomposition of the real per capita GDPs

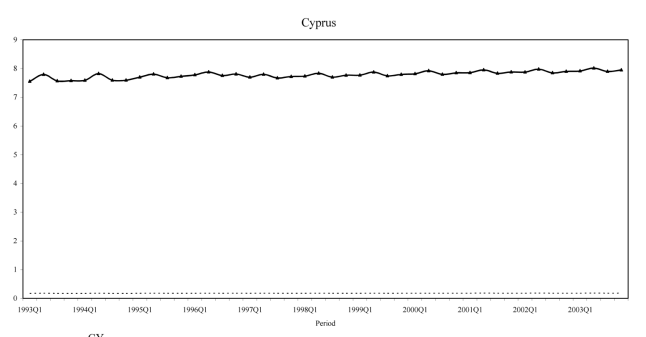

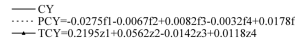
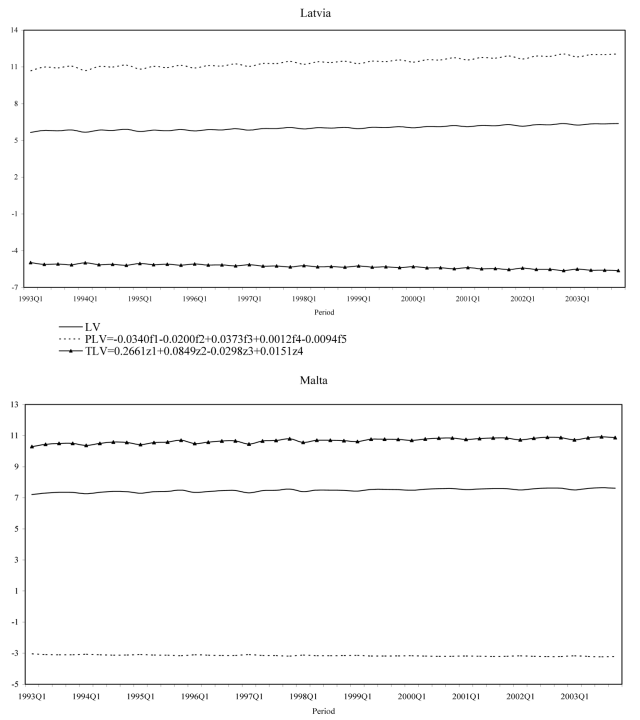

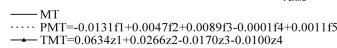

Slovenia

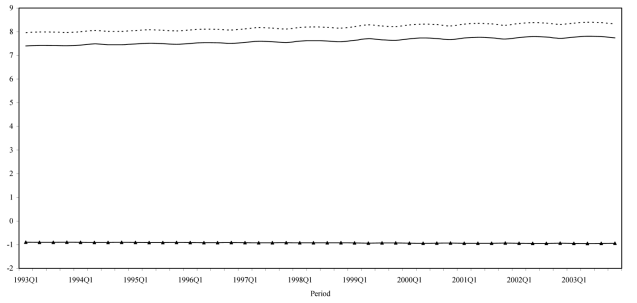

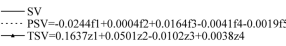

Germany

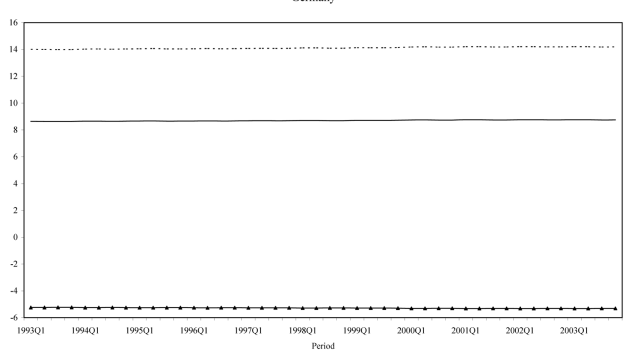

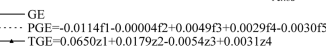

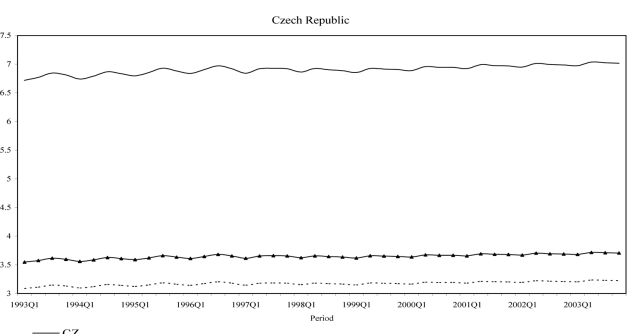

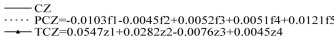

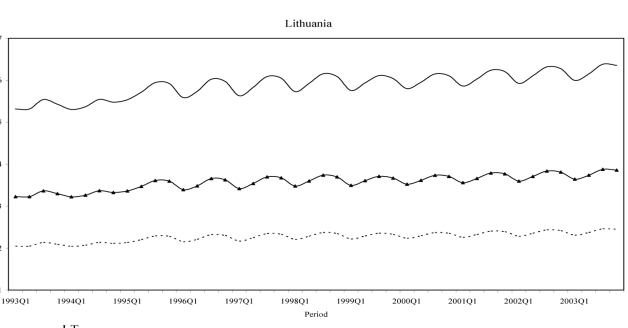

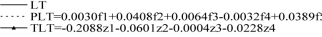

Slovak Republic

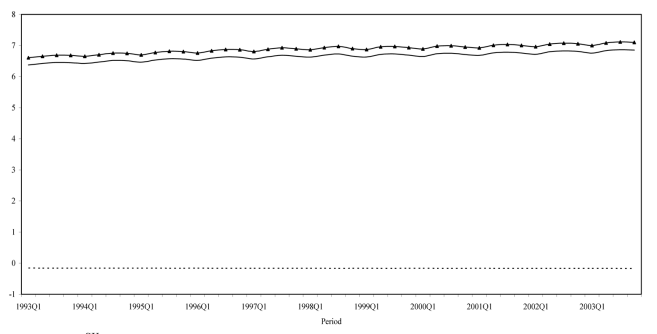

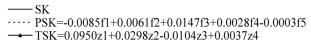

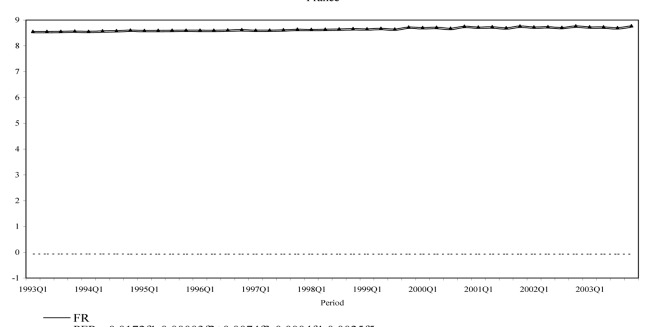

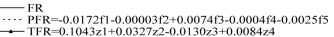


the long run. Alternatively, each of the new EU countries and the 2 EMU countries set their financial policies independently of each other.

For the real exchange rates, we tested two hypotheses. First, that the six countries identified in Figure 3 (i.e. the Czech Republic, Hungary, Malta, Poland, Slovenia and France) contribute significantly to the six common trends. Second, that the "enlargement core" together with France dominate the six common trends. As Table 4 indicates, both hypotheses are rejected at the 5 percent level. Thus, the real exchange rates of the new EU countries behave independently from the French real exchange rate.

For real per capita GDPs, we also tested two hypotheses. First, that the five countries indicated by Figure 4 (i.e., the Czech Republic, Latvia, Malta, Slovenia and Germany) have a common permanent component among the five common trends. As shown in Table 4 this hypothesis is rejected. Second, that the "enlargement core" jointly with the 2 EMU countries contribute significantly to the five common trends. The reason for the latter hypothesis is that, following the breakup of the former Soviet bloc, the Czech Republic, Hungary and Slovenia adopted market oriented reforms including privatization and opening up to trade. Further, Cyprus and Malta have been traditionally open market economies, and all the enlargement core countries had applied, since the mid-1990s, for membership

Figure 5. The inflation rates of the Czech Republic, Estonia, Hungary and Germany

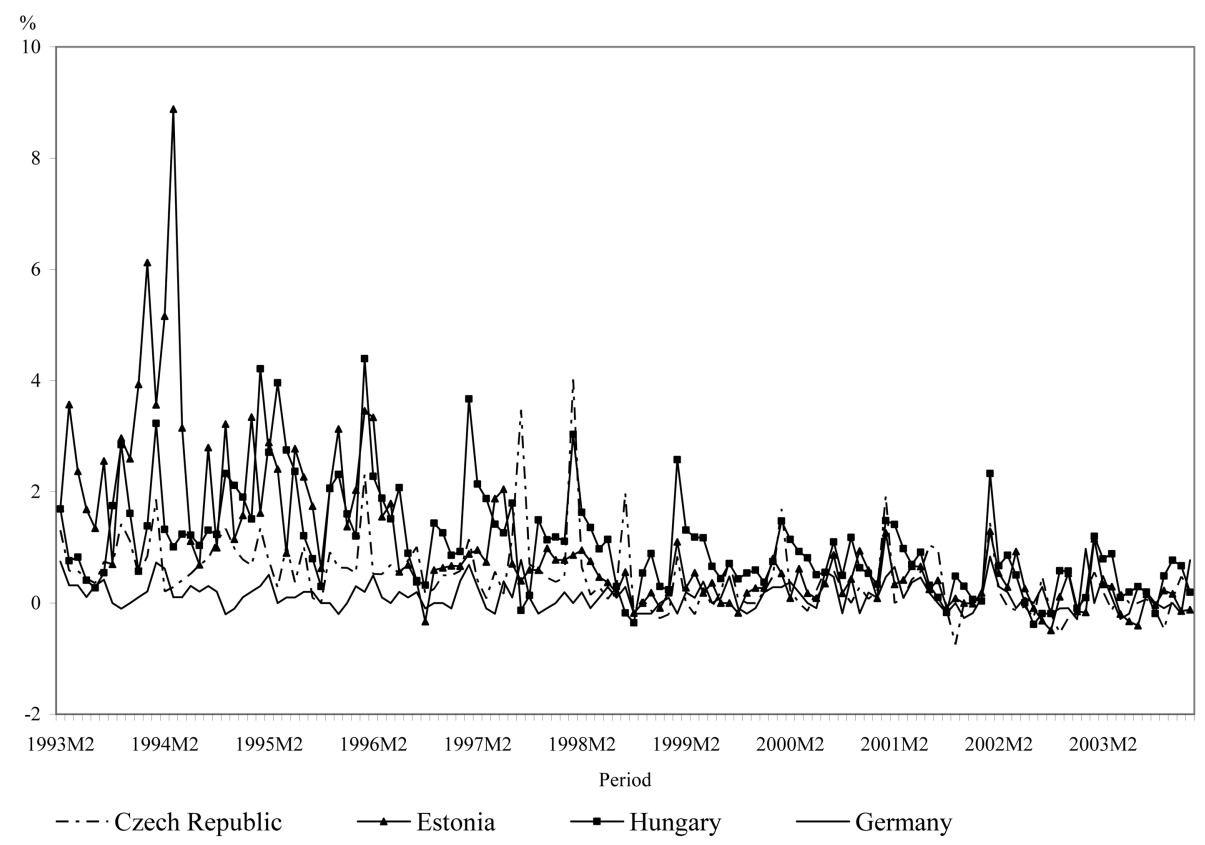


into the EU. Presumably, one would expect their economic structures to converge over time to those of France and Germany. However no such evidence exists in the data, as the null hypothesis that the seven countries have a common long memory component among the five common trends is also rejected at the 5 percent level of significance.

In summary, our empirical results indicate that there are no linear combinations of countries that posses a long memory component among the common trends in the systems of nominal exchange rates, long term interest rates, real exchange rates and real per capita GDPs. This evidence, in turn, implies that the new EU countries and the 2 EMU countries both set their policies independently and that their economic structures are largely dissimilar.

As an alternative check of cross national long run economic interdependence, we finally tested for cointegration among the estimated common trends in the systems of nominal exchange rates, long term interest rates, real exchange rates and real per capita GDPs. Table 5 reports the cointegration tests results in this case. The Trace test statistics indicate no cointegration either in the 5-dimensional system of common trends for the nominal exchange rates or the 7-dimensional system of common trends for the long term interest rates. The 6-dimensional system of the common trends for the real exchange rates and the 5-dimensional system of the common trends for the real per capita GDPs each possess only one cointegrating vector respectively. These findings complement the earlier results of

Table 5. Testing for interdependence among the common trends: Trace statistics

\begin{tabular}{ccccccc}
\hline$(p-r)$ & $\begin{array}{c}\text { Nominal } \\
\text { exchange } \\
\text { rates }\end{array}$ & $\begin{array}{c}\text { Long term } \\
\text { interest rates }\end{array}$ & $\begin{array}{c}\text { Real } \\
\text { exchange } \\
\text { rates }\end{array}$ & $\begin{array}{c}\text { Real } \\
\text { per capita } \\
\text { GDPs }\end{array}$ & $\begin{array}{c}5 \% \text { critical } \\
\text { values for } \\
\text { Model 0 }\end{array}$ & $\begin{array}{c}5 \% \text { critical } \\
\text { values for } \\
\text { Model 1* }\end{array}$ \\
\hline 7 & & 104.34 & & & 111.79 & 134.70 \\
6 & & 70.74 & $117.08^{*}$ & & 83.94 & 103.84 \\
5 & 55.29 & 46.06 & 76.23 & $101.98^{*}$ & 60.06 & 76.96 \\
4 & 29.42 & 28.41 & 40.10 & 52.99 & 40.17 & 54.09 \\
3 & 16.30 & 15.94 & 21.69 & 25.18 & 24.28 & 35.19 \\
2 & 8.18 & 8.79 & 10.74 & 13.83 & 12.32 & 20.25 \\
1 & 2.33 & 2.52 & 3.42 & 3.21 & 4.13 & 9.17 \\
$k^{\text {a }}$ & 2 & 1 & 3 & 2 & & \\
Model & $1^{*}$ & 0 & $1^{*}$ & $1^{*}$ & & \\
\hline
\end{tabular}

The value reported at the top of each column is for $r=0$, so that $p-r=p$, where $p$ is the number of common trends included. *denotes rejection of the null hypothesis of at most $r$ cointegrating relations at the $5 \%$ significance level. ${ }^{a} k$ indicates the lag intervals. 
the paper and point, similarly, to weak partial convergence among the policies of the new EU countries and the 2 EMU countries.

Overall the empirical results indicate minimal long run interdependence among the key macroeconomic variables of the 10 new EU countries and the 2 core EMU countries. They underline the need for further adjustments in the policies and economic structures of the new EU countries if they wish to join the EMU in the future.

There are clear policy implications from these findings for the new EU countries. First, the lack of convergence of real and nominal exchange rates to a single common trend necessitates the need for the new EU countries to join the exchange rate mechanism II (ERM II) of the EMU in order to reduce wide fluctuations and stabilize their exchange rates. Second, joining the ERM II will also help the new EU countries to achieve quicker convergence of their nominal and real interest rates, given that they have made significant progress in reducing their inflation rates. Third, the lack of cointegration in deficit/GDP and debt/GDP ratios among the new EU countries implies the need to change their fiscal policies, in the direction of reducing deficits and debts over time, in order to meet the targets set by the Maastricht Treaty.

\section{Concluding Remarks}

In this paper we have used cointegration and common trends analysis in order to study the co-movements of certain key macroeconomic variables among the ten new EU countries and the two core EMU countries, France and Germany. These variables were drawn from the nominal convergence criteria laid down by the Maastricht Treaty for successful participation in the EMU, and two aspects of real convergence proxied by the real exchange rates and the real per capita GDPs of these countries.

The cointegration results indicate weak partial convergence in the cases of nominal exchange rates, long term interest rates, real exchange rates and real per capita GDPs, as the number of common trends is greater than the number of cointegrating relations. For the deficit/GDP and debt/GDP ratios the results indicate no cointegration. Only for the inflation differentials relative to Germany we find evidence of full convergence.

By decomposing each system of variables into its permanent and transitory components, we also tested whether or not a given country or a group of countries 
contribute significantly to a common permanent component among the common trends in the sets of variables we analyzed. In every instance no such evidence exists in the data. Also we found minimal linkages, if any, among the common trends for nominal exchange rates, long term interest rates, real exchange rates and real per capita GDPs, pointing to the lack of long run interdependence among the economies of these countries.

Overall, our empirical findings indicate weak partial convergence of policies and economic structures among the new EU countries and the two core EMU countries, and support the view that the new countries are not ready to join the EMU at present. Additional work is required by the new EU countries in order to achieve nominal and real convergence relative to the EMU countries. Our results emphasize the need for greater coordination in monetary and fiscal policies of the new EU countries, if they wish to join the EMU in the future.

\section{Acknowledgements}

We would like to thank the participants of the conference "Asymmetries in Trade and Currency Arrangements in the 21st Century", Frankfurt, July 2004, and the seminar participants at the Departments of Economics, University of Cyprus and the University of Crete for useful comments and suggestions. The first author would also like to thank the Social Sciences and Humanities Research Council of Canada for financial support.

Received 12 June 2006, Accepted 10 October 2006

\section{References}

Barro, J.R and Sala-i-Marin X. (1995) Economic Growth, McGraw-Hill Inc, UK.

Bayoumi, T. and Taylor, M.P. (1995) Macroeconomic Shocks, the ERM and Tripolarity, Review of Economics and Statistics, 77, 321-331.

Engle, R.F. and Granger, C.W.J. (1987) Cointegration and Error Correction: Representation, Estimation and Testing, Econometrica, 55, 251-276.

Gonzalo, J. and Granger, C.W.J. (1995). Estimation of common long-memory components in cointegrated systems. Journal of Business and Economic Statistics, 13, 27-35.

Hafer, R.W. and Kutan, A.M. (1994) A Long Run View of German Dominance and the Degree of Policy Convergence in the EMS, Economic Inquiry, 32, 684-695. 
Haug, A.A., MacKinnon, J.G. and Michelis, L. (2000) European Monetary Union: A Cointegration Analysis, Journal of International Money and Finance, 19, 419-432. International Monetary Fund (2004) International Financial Statistics (IFS) CD-ROM, International Monetary Fund, Washington DC.

Johansen, S. (1994) The Role of the Constant and Linear Terms in Cointegration Analysis of Nonstationary Variables, Econometric Reviews, 13, 205-229.

Johansen, S. (1995) Likelihood-based Inference in Cointegrated Vector Autoregressive Models, Oxford University Press, Oxford.

Johansen, S. and Juselius, K. (1990) Maximum Likelihood Estimation and Inference on Cointegration with Applications to the Demand for Money, Oxford Bulletin of Economics and Statistics 52, 169-210.

Karfakis, S.J. and Moschos, D.M. (1990) Interest Rates Linkages within the European Monetary System: A Time Series Analysis, Journal of Money, Credit and Banking, 22, 388-394.

MacDonald, R. and Taylor, M.P. (1991) Exchange Rates, Policy Convergence and the European Monetary System, Review of Economics and Statistics, 73, 553-558.

MacKinnon, J.G., Haug, A.A. and Michelis, L. (1999) Numerical Distribution Functions of Likelihood Ratio Tests for Cointegration, Journal of Applied Econometrics, 14, 563-577.

Osterwald-Lenum, M. (1992) A Note with Quantiles of the Asymptotic Distribution of the Maximum Likelihood Cointegration Rank Test Statistics, Oxford Bulletin of Economics and Statistics, 54, 461-471. 